\title{
Effects of Carbonation on the Microporosity and Macro Properties of Portland Cement Mortar CEM I
}

\author{
Son Tung Pham \\ Laboratory of Civil Engineering and Mechanical Engineering, Department of Civil Engineering, National \\ Institute of Applied Sciences, Rennes, France \\ Email: spham@insa-rennes.fr; phamsontung82@yahoo.com
}

Received 7 April 2014; revised 6 May 2014; accepted 6 June 2014

Copyright @ 2014 by author and Scientific Research Publishing Inc. This work is licensed under the Creative Commons Attribution International License (CC BY). http://creativecommons.org/licenses/by/4.0/

c) (†) Open Access

\section{Abstract}

The aim of this work was to examine the microstructural changes of CEM I standardised cement mortar caused by accelerated carbonation $\left(20 \% \mathrm{CO}_{2}\right.$ concentration) using porosity accessible to water and nitrogen adsorption. The conflicted results obtained by these two techniques showed the differences in porous domains explored, while the pore size distributions calculated from nitrogen adsorption provided evolution of the micro and meso pores during carbonation. The porosity accessible to water showed changes in all three porous domains: macro, meso and micro pores. This is because of difference in the molecular sizes between water and nitrogen molecules. Although these two techniques are different, they help to complementarily evaluate the effects of carbonation. The results also indicated the influence of type of cement on microstructural evolutions and the correlation between variations of mesopores volume and specific surface area. Changes in microstructure induce changes in macroscopic properties that we also examined such as the solid phase volume using helium pycnometry, the gas permeability, the thermal conductivity, the thermal diffusivity, and the longitudinal and transverse ultrasonic velocities.

\section{Keywords}

Carbonation, Cement Mortar, Microstructure, Nitrogen Adsorption, Intrinsic Gas Permeability, Thermal Conductivity, Thermal Diffusivity, Ultrasonic Velocities, Helium Pycnometry

\section{Introduction}

Carbon dioxide from the air can react with the portlandite $\mathrm{Ca}(\mathrm{OH})_{2}$ and the calcium silicate hydrate C-S-H in 
concrete to form calcium carbonate $\mathrm{CaCO}_{3}$. This process is called carbonation, which is a natural aging process for all cement materials. The principle reactions are:

$$
\begin{gathered}
\mathrm{CO}_{2}+\mathrm{Ca}(\mathrm{OH})_{2}=\mathrm{CaCO}_{3}+\mathrm{H}_{2} \mathrm{O} \\
\mathrm{C}_{x} \mathrm{~S}_{y} \mathrm{H}_{z}+x \mathrm{H}_{2} \mathrm{CO}_{3}=x \mathrm{CaCO}_{3}+y \mathrm{SiO}_{2} \cdot t \mathrm{H}_{2} \mathrm{O}+(x-t+z) \mathrm{H}_{2} \mathrm{O}
\end{gathered}
$$

The progress of these carbonation reactions causes microstructural changes, which can be highlighted by various parameters such as variations in porosity, specific surface area and pore size distribution. At a larger scale, these changes in microstructure lead probably to changes in macro physical properties such as the solid phase volume, the gas permeability, the thermal properties, and the propagation velocities of ultrasonic waves.

Another effect of carbonation is the decrease in $\mathrm{pH}$ due to the consummation of $\mathrm{Ca}(\mathrm{OH})_{2}$, which induces the depassivation and corrosion of the steel rebar. The service time of the reinforced concrete structure is often considered as the duration for $\mathrm{CO}_{2}$ to reach the rebar. The onset of the corrosion can be predicted by the assessment of durable indicators [1], especially the gas permeability. However, the correlation between this parameter and the carbonation durability is still in doubt. While most authors have observed a decrease in the porosity accessible to water [2] [3], this result can not explain the increase in the gas permeability observed by some authors [2] [4]. This is because the decrease in water porosity after carbonation means that the totality of pores decreases, but no specific information about the meso and macro pores, the porous domains which influence the gas permeability, can be drawn.

Furthermore, some investigators believe that the water molecule with a small radius of $0.1 \mathrm{~nm}$ [5] can penetrate not only into meso and macro pores (radius larger than $2 \mathrm{~nm}$ ) but also into nano and micro pores. In contrast, the nitrogen molecule can not enter the small pores because of its larger radius of $0.21 \mathrm{~nm}$ [6]. Hence, these two techniques do not necessarily explore the same porous domains.

For these reasons, we propose to investigate the evolution of the microstructure caused by the carbonation in a cementitious matrix (CEM I cement mortar) using nitrogen adsorption, which is suitable for meso pores with radii of $2 \mathrm{~nm}$ to $32 \mathrm{~nm}$ [7]. We will report changes in the BET specific surface area [8], the pore size distribution, and the porosity accessible to water. Changes in microstructural level will help to discuss the evolutions of macro properties that we propose to measure, such as the solid phase volume, the gas permeability, the thermal conductivity, the thermal diffusivity, the longitudinal and transverse ultrasonic velocities. Although the thermal conductivity is important for fire resistance and energy conservation, its evolution during carbonation of cement materials has rarely been studied.

\section{Materials and Methods}

\subsection{Standardised Mortar CEM I}

For this study, we used a normalised mortar prepared with Lafarge cement CEM I 52.5 N PM-ES-CP2 and French standard sand certified in accordance with norm EN 196-1 and ISO 679:2009. The water/cement and sand/cement ratios were respectively 0.5 and 3 . At the end of the mixing, the mortar was placed in cylindrical moulds ( $\varnothing=40 \mathrm{~mm}, \mathrm{~h}=60 \mathrm{~mm}$ ). The samples were demoulded after 24 hours and then cured for 90 days in a humid chamber $\left(20^{\circ} \mathrm{C}, 100 \%\right.$ relative humidity).

The cement CEM I was chosen because of its basic originality. Moreover, Bier et al. [9] observed the creation of meso pores after carbonation of a mortar, which was not rich in portlandite and contained fly ash. This is not the case of CEM I, therefore it was chosen for this study because we want to find out if this basic cement is also subjected to significant changes in the domains of meso and macro pores.

\subsection{Accelerated Carbonation}

Before carbonation, the samples were dried at $105^{\circ} \mathrm{C}$ to a constant mass and then stored for 7 days at $20^{\circ} \mathrm{C}, 65 \%$ relative humidity for homogenisation in the internal humidity [10]. To implement an axial carbonation, the samples were protected laterally using an adhesive tape and then put into an environmentally controlled chamber at $20^{\circ} \mathrm{C}$, $65 \%$ relative humidity and $20 \% \mathrm{CO}_{2}$ concentration for a defined time. At the end of the carbonation period, the carbonated zone was determined using phenolphthalein test. 


\subsection{Nitrogen Adsorption}

To study the mesoscopic scale, we record the nitrogen adsorption-desorption isotherms at $77 \mathrm{~K}$ on grinding powders originating from the samples. The specific surface area analyser Micromeritics Gemini VII was used for this test. From adsorption desorption isotherms of nitrogen, the BET specific surface area [8] and the BJH pore size distribution [11] were calculated.

\subsection{Gas Permeability}

The test was performed in a helium permeameter under variable pressures: 1, 2, 3 and 5 bars. For each pressure, we waited for the gas debit to become constant by using a flow meter. The intrinsic permeability $\mathrm{K}$ was then calculated in accordance with CEMBUREAU method [12].

\subsection{Thermal Properties}

The thermal properties were performed at $20^{\circ} \mathrm{C}$ using a Hot Disk Thermal Constants analyser TPS2500S. A plane Hot Disk sensor was fitted between two pieces of the sample-each one with a plane surface facing the sensor. By passing an electrical current, high enough to increase the temperature of the sensor between a fraction of a degree up to several degrees, and at the same time recording the resistance (temperature) increase as a function of time. The Hot Disk sensor was used both as a heat source and as a dynamic temperature sensor.

\subsection{Helium Pycnometry}

The solid volume was determined using Micromeritics helium pycnometry AccuPyc II 1340. This helium pycnometry method consists of injecting a gas at a given pressure in a container of known internal volume containing the sample and then relaxing it in a second chamber of known volume. The measure of the new equilibrium pressure is used to calculate the actual volume of the sample using the ideal gas law.

\subsection{Propagation Velocities of Ultrasonic Waves}

The ultrasonic setup is composed of a pulse generator and receiver SOFRANEL model 5800 PR, two piezoelectric transducers of longitudinal waves and two piezoelectric transducers of transverse waves, a computer for data acquisition and data processing with a card oscilloscope/digitizer of $20 \mathrm{MHz}$ sampling frequency, and a program of acquisition and signal processing developed under LabView environment.

\section{Results and Discussion}

\subsection{Changes in Microstructure of CEM I Mortar Caused by Carbonation}

\subsubsection{Nitrogen Adsorption Desorption Isotherms}

The nitrogen adsorption desorption isotherms for the two types of samples (well-carbonated and non-carbonated) are presented in Figure 1. We observe that the quantity of adsorbed nitrogen on the carbonated sample is more significant than on the non-carbonated one.

Regarding the pore distribution curves (Figure 2), we observe that the carbonation results in a decrease in the micropore volume and an increase in the mesopore volume with radius around $2 \mathrm{~nm}$. For the mesopores with radius larger than $2 \mathrm{~nm}$, the increase in their volume is insignificant. The carbonation of portlandite is manifested by the crystallisation of numerous calcite crystals on the portlandite plates [13]. Thus, it is understandable that the carbonation results in an increase in the specific surface area (Table 1) and a modification of the pore network. However, the increase in the specific surface is very slight and can be considered insignificant. This is probably due to the insignificant increase of the mesopore volume of CEM I cement mortar. This result shows clearly that the cement materials based on CEM I and composed cements (CEM II, III, etc.) behave differently during carbonation: the increase in mesopore volume is more significant in composed cement materials than in CEM I cement materials.

While the decrease in volume of micropores is attributed to the formation of $\mathrm{CaCO}_{3}$ which clogs the pores, causes of the increase in the volume of mesopores is still discussed. According to Eitel [14], the increase in mesopore volume is caused by the porous structure of the silica gels that are formed during the carbonation. 


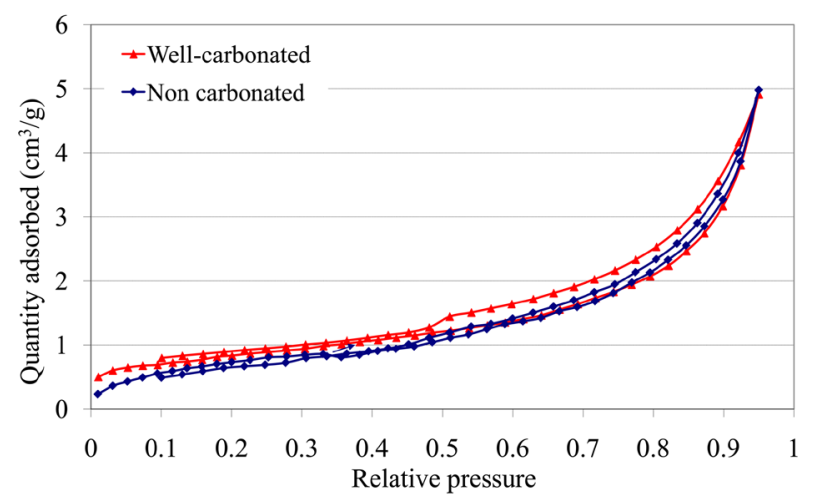

Figure 1. Nitrogen adsorption desorption on the powder sample.

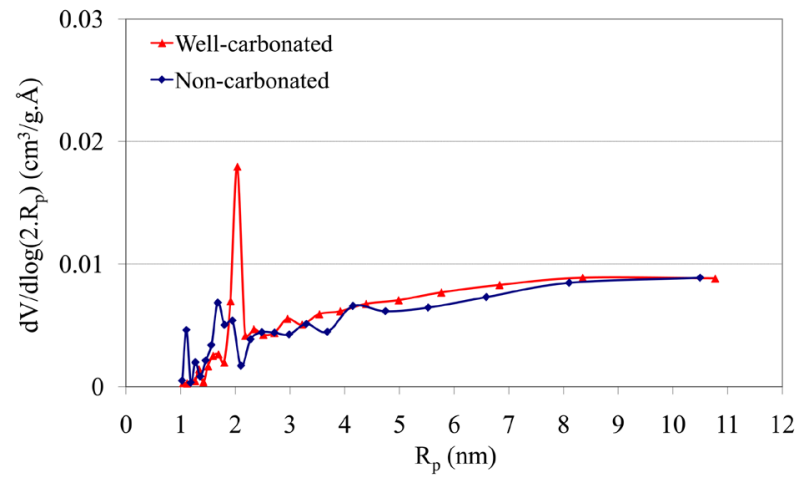

Figure 2. Pore size distribution determined from nitrogen desorption branch of the powder sample.

Table 1. Specific surface area of non-carbonated and well-carbonated mortars.

\begin{tabular}{cc} 
& $\mathrm{BET}_{\text {nitrogen }}\left(\mathrm{m}^{2} / \mathrm{g}\right)$ \\
\hline Non-carbonated & $2.5 \pm 0.6$ \\
Well-carbonated & $3.0 \pm 0.5$ \\
\hline
\end{tabular}

Swenson and Sereda [15] reported that the increase in mesopores is caused by cracks in the $\mathrm{CaCO}_{3}$ gangue that surrounds the portlandite crystals. Other authors have attributed the increase in mesopores to carbonation shrinkage [16]. Our Scanning Electron Microscopy (SEM) images of the cement mortars before and after carbonation show clearly apparition of micro cracks due to carbonation shrinkage (Figure 3).

\subsubsection{Total Porosity}

The porosity accessible to water before and after carbonation determined using hydrostatic weighing [17] are presented in Table 2. We observe a clear decrease in the total porosity. This result is therefore opposite in comparison with the slight increase in the cumulative pore volume obtained by the nitrogen adsorption (Figure 4). Both techniques seem to cover different porous domains.

According to Belie et al. [6], the size of nitrogen molecules (radius $0.21 \mathrm{~nm}$ ) does not allow them to access the microporosity, whereas the water molecules (radius $0.1 \mathrm{~nm}$ ) can enter these micropores. Hence, the results of nitrogen adsorption provide information mainly about the mesoporous domain.

In the domain of nano and micro pores, the calcium carbonate formed during carbonation obstructs the pores, by consequence, the water accessible porosity decreases. Some investigators believe that a major fraction of water molecules taken up by the sample enters spaces between the C-S-H rather than to be adsorbed on the existing surface. Hence, the results of porosity accessible to water provide information mainly about the nano and micropores. The decrease in the volume of micropores inferred from porosity accessible to water was also con- 


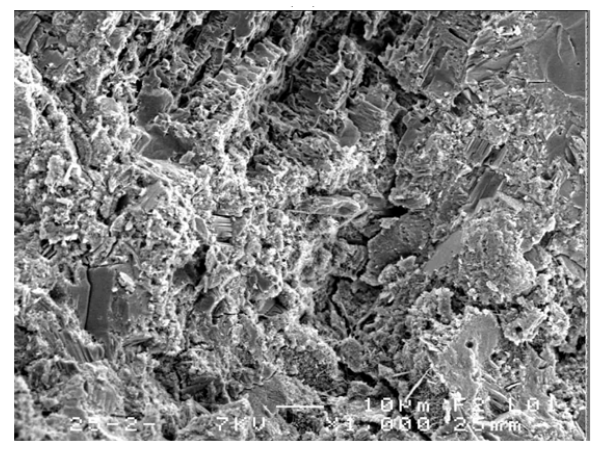

(a)

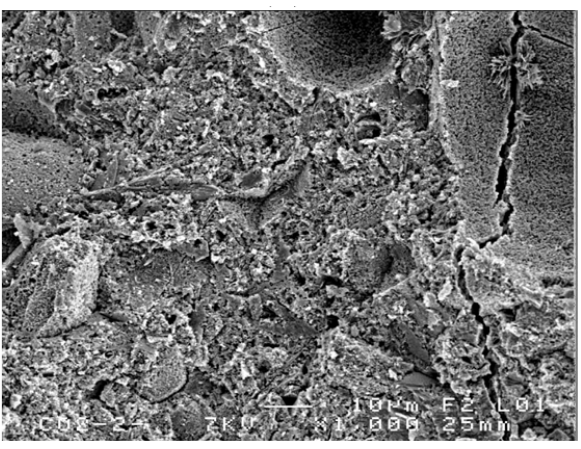

(b)

Figure 3. SEM images of non-carbonated (a) and well-carbonated (b) cement mortars.

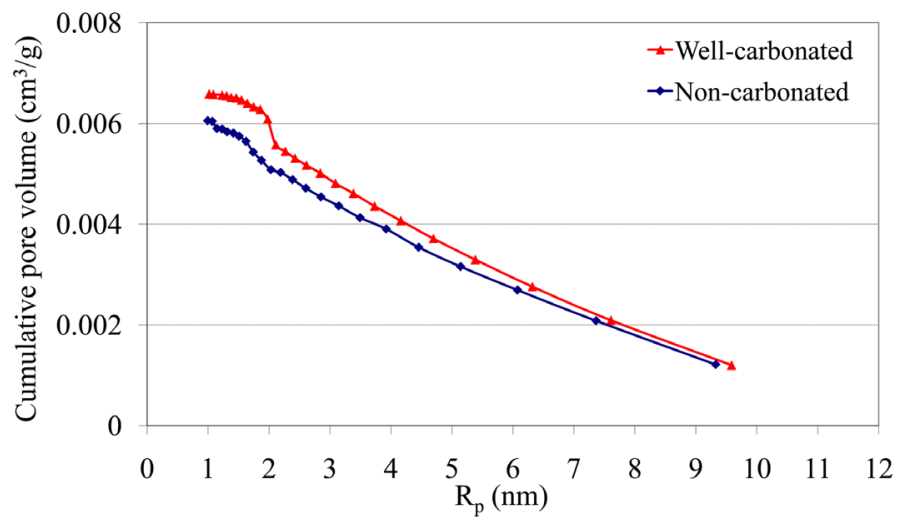

Figure 4. Cumulative pore volume determined by nitrogen adsorption.

Table 2. Water-accessible porosity of non-carbonated and well-carbonated mortars.

\begin{tabular}{cc}
\hline & Porosity (\%) \\
\hline Non carbonated & $16.4 \pm 0.2$ \\
Well carbonated & $11.6 \pm 0.2$ \\
\hline
\end{tabular}

firmed in Figure 2 where we presented the pore size distribution calculated from nitrogen adsorption desorption isotherms.

\subsection{Changes in Macro Physical Properties of CEM I Mortar Caused by Carbonation}

\subsubsection{Mass Gain}

The carbonation Reactions (1), (2) shows that a quantity of $\mathrm{CO}_{2}$ was captured to give $\mathrm{CaCO}_{3}$ as a product of carbonation. Also, water released by calcium hydroxide and C-S-H on carbonation may aid the hydration of the unhydrated cement. For this reason, all the mass were measured at dry state to reflect only the gain in mass of the solid phase. An electronic scale was used to measure the mass increase of the specimens due to $\mathrm{CO}_{2}$ uptake. $\mathrm{CO}_{2}$ uptake was determined by the initial mass and the final carbonated mass as shown in Equation (3):

$$
\Delta m=\frac{m_{\text {after carbonation }}-m_{\text {before carbonation }}}{m_{\text {before carbonation }}} \times 100 \%
$$

We observe in Figure 5 that the mass increases in a continuous manner. On the other hand, the apparent volume of the specimens remains constant during carbonation. Therefore, we deduce an increase in the density of the mortar after carbonation, which is confirmed by the measures presented in Figure 6. Hence, the carbonation leaded to a densification of the microstructure. 


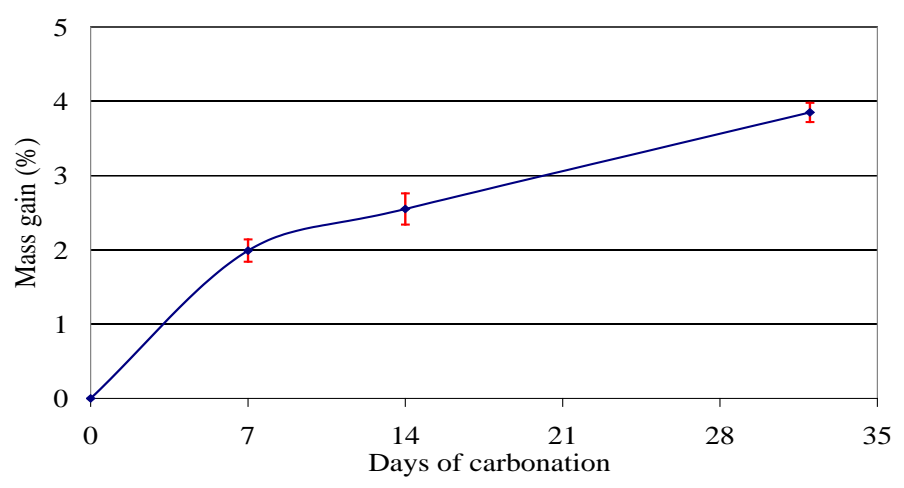

Figure 5. Mass gain during carbonation of cement mortar.

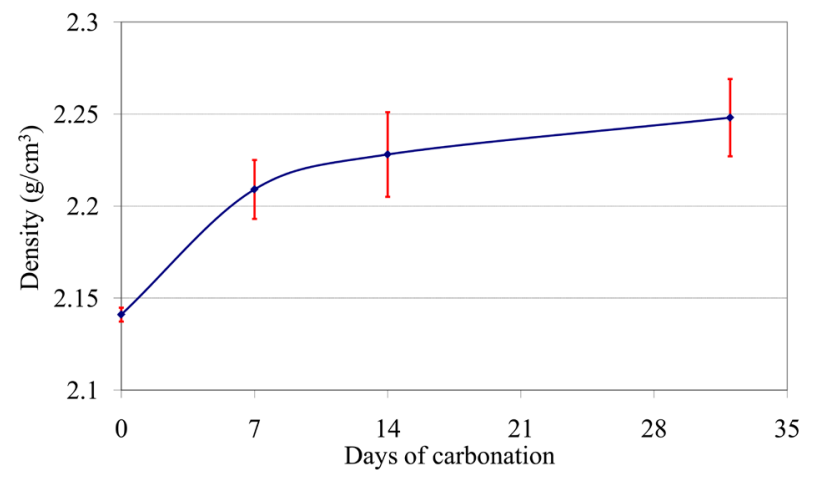

Figure 6. Evolution of the density of cement mortar during carbonation.

\subsubsection{Carbonation Depth}

The propagation of $\mathrm{CO}_{2}$ in the cement mortar was revealed by spraying phenolphthalein solution onto the fresh surfaces of samples. We observe in Figure 7 that the carbonation rate in an accelerated carbonation process is much more rapid than in natural carbonation where it can take several years for a penetration of just several millimetres [1].

Furthermore, the calcite formed during carbonation covers the crystals of portlandite, and thus slows the carbonation rate because it becomes more difficult for $\mathrm{CO}_{2}$ to reach the portlandite. This explains why we observe the most important rate of propagation after the first 7 days of carbonation in comparison with the results at 14 and 32 days.

Although the samples were protected laterally in order to execute an axial carbonation, as a very active gas, the $\mathrm{CO}_{2}$ still penetrated from the sides as shown in Figure 7. The carbonation depth was thus measured mostly in the middle of the sample in order to eliminate the effects of two-dimension carbonation. Moreover, the bottom of the sample is denser than the top of the sample due to the segregation of aggregates during preparation of cement mortar, which results in a more important carbonation depth at the top than at the bottom of the sample.

In Figure 8, we observe that the carbonation propagation is not always a linear function with the square root of the duration of carbonation: $x=A \cdot \sqrt{t}$ [1], where $A$ is a constant taking into account both the composition of the cement material (water/cement ratio, type of binder...) and the environmental conditions (relative humidity, temperature, pressure...). This simple linear modelling of carbonation depth is therefore not always applicable. This is because the coefficient A depends actually on the porosity which decreases during carbonation (Figure 9), therefore A decreases and the slope of the graph in Figure 8 changes.

\subsubsection{Gas Permeability}

Measures of gas permeability were performed with the experimental setup as described in Figure 10.

Gas permeability is measured using Helium gas according to recommendation standard RILEM TC 116-PCD [18]. Apparent permeability $\left(K_{a}\right)$ is calculated from the Hagen-Poiseuille equation for laminar flow of a com- 


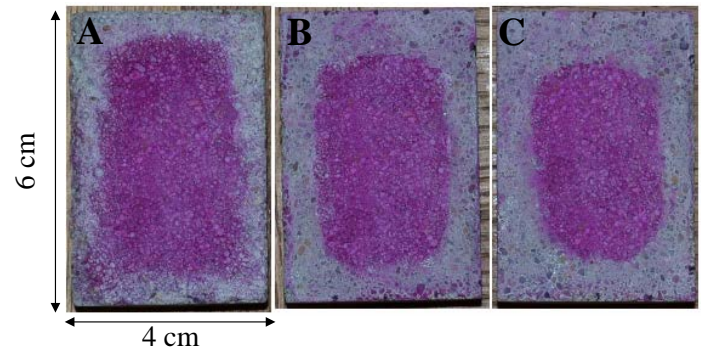

Figure 7. Propagation of $\mathrm{CO}_{2}$ revealed by phenolphthalein test on samples carbonated for 7 days (A), 14 days (B) and 32 days (C).

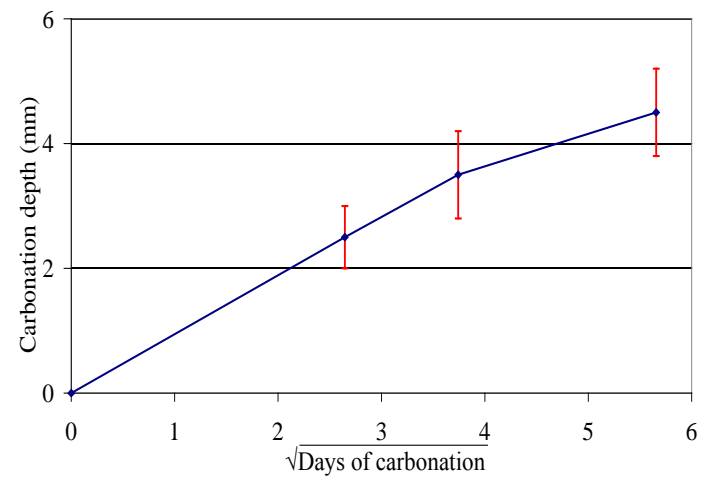

Figure 8. Evolution of the carbonation depth during carbonation.

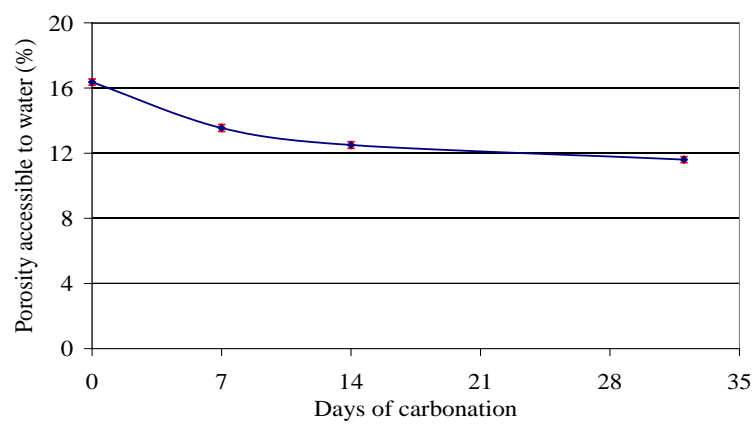

Figure 9. Evolution of the porosity accessible to water during carbonation.

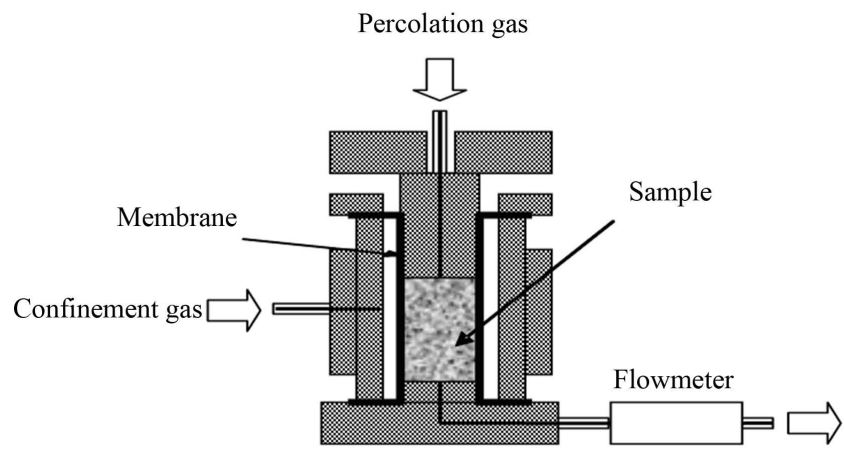

Figure 10. Scheme describing the experimental setup of permeability test. 
pressible fluid through a porous body under steady state conditions according to formula (4).

$$
K_{a}=\frac{2 \cdot Q \cdot P_{\text {atm. }} L \cdot \mu}{A\left(P_{i}^{2}-P_{\text {atm }}^{2}\right)}
$$

where; $K_{a}$ : apparent permeability to gas of the specimen $\left(\mathrm{m}^{2}\right)$ at fixed pressure (in our case at 1, 2, 3 and 5 Bars); $L$ : length of the sample (m); $Q$ : measured gas flow $\left(\mathrm{m}^{3} / \mathrm{s}\right)$; A: cross-sectional area $\left(\mathrm{m}^{2}\right) ; \mu$ : coefficient of viscosity of the gas (Pa.s); $P_{i}$ : applied absolute pressure $=$ upstream pressure $(\mathrm{Pa}) ; P_{a t m}$ : atmospheric pressure $=$ downstream pressure $(\mathrm{Pa})$. The intrinsic coefficient $\mathrm{K}$ is obtained by the intersection of the line connecting $K_{a}$ values in function of $1 / P_{i}$ with the coordinate axis.

Figure 11 presents the evolution of the gas intrinsic permeability during carbonation. Contrary to what we expected, an increase in the gas intrinsic permeability was observed. The results seem to be in conflict with the decrease of the porosity. However, the water porosity decreases after carbonation means that the totality of pores decreases, but we have no specific information about the meso and macro pores. By combination with the pore size distribution calculated from nitrogen adsorption, we have concluded that the carbonation resulted in an increase in the volume of mesopores at the expense of the volume of micropores. Therefore, it seems that the evolution of the gas permeability during carbonation is largely influenced by the changes in mesoporous domain: the increase in the volume of mesopores is the cause of the increase in the gas intrinsic permeability. The gas permeability was not influenced by the decrease in the volume of micropores.

It is also important to note that the increase in the gas permeability is not really significant. This result is in perfect correlation with the insignificant increase of the mesopores volume with radius larger than $2 \mathrm{~nm}$. Indeed, we only observed a clear increase in the volume of pores with radius around $2 \mathrm{~nm}$.

\subsubsection{Thermal Properties}

We present in Figure 12 the evolution of the thermal conductivity of CEM I mortar during carbonation. One measure was taken at $65 \%$ of relative humidity, another was taken when the specimens were dried. We observe an increase in the thermal conductivity as a function of the carbonation duration. Due to the low thermal conductivity of the air, the thermal conductivity varies with the density [19]. Hence, the increase in the thermal conductivity during carbonation is coherent with the decrease of the total porosity.

The results show that the thermal conductivity at dry state is smaller than that obtained at $65 \%$ relative humidity. For building materials, it is common to use the following equation to show influence of the relative humidity on the thermal conductivity:

$$
\lambda=k \cdot \lambda_{0} \mathrm{e}^{0.08 H}
$$

where $k$ is a coefficient of dimension, $\lambda_{0}$ is the thermal conductivity of dry material, and $H$ is the relative humidity in percentage. The values of $k$ were calculated and presented in Table 1 . We observe that $k$ increases and remains stable after carbonation. $k$ is a characteristic coefficient which is unique for each material, it is therefore understandable that $k$ remains stable once the cement mortar is carbonated (see Table 3).

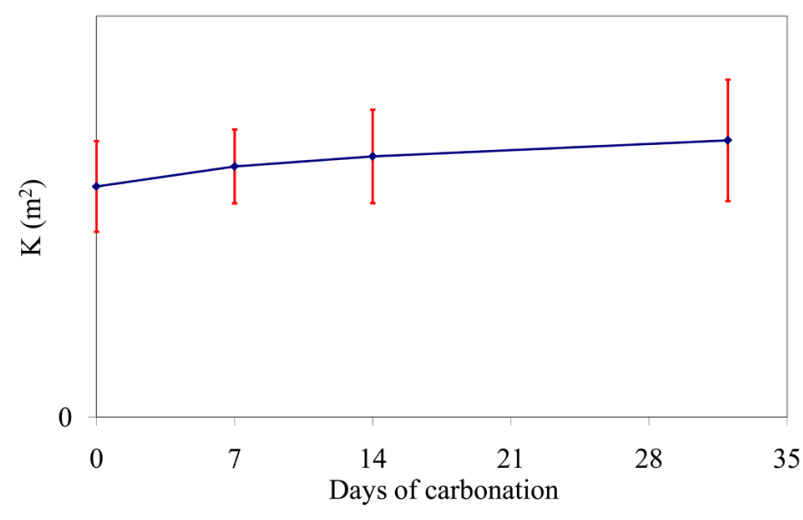

Figure 11. Evolution of the intrinsic permeability to helium during carbonation. 


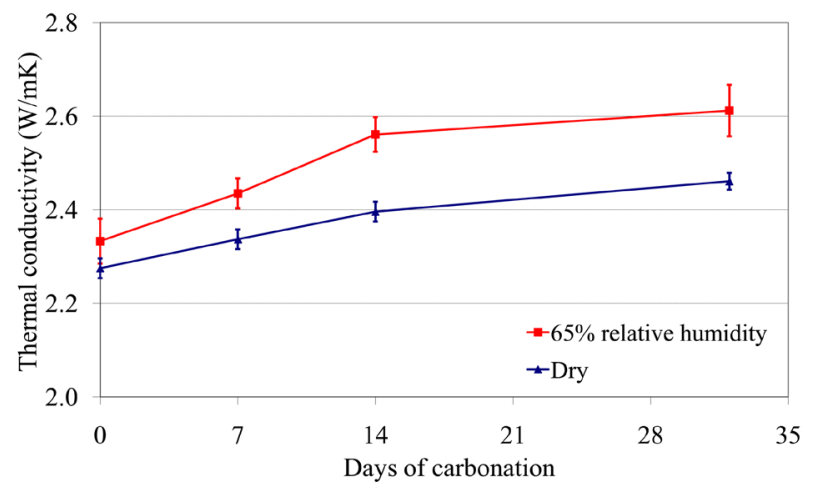

Figure 12. The thermal conductivity during carbonation measured at $65 \%$ relative humidity and at dry state.

Table 3. Coefficient of dimension $\mathrm{k}$ of mortar during carbonation.

\begin{tabular}{cc}
\hline Days of carbonation & $\mathrm{k}$ \\
\hline 0 & $0.0062 \pm 1.41 \mathrm{E}-05$ \\
7 & $0.0067 \pm 4.65 \mathrm{E}-05$ \\
14 & $0.0068 \pm 1.37 \mathrm{E}-04$ \\
32 & $0.0068 \pm 1.35 \mathrm{E}-04$
\end{tabular}

The evolution of the thermal diffusivity is similar to the case of the thermal conductivity. Effectively, we observe also an increase in the thermal diffusivity (Figure 13). These results show that the carbonated cement mortar is more sensible to heat transfer than the non-carbonated one.

\subsubsection{Propagation Velocities of Ultrasonic Waves}

We present the evolutions of longitudinal $\left(V_{L}\right)$ and transverse $\left(V_{T}\right)$ ultrasonic velocity in Figure 14 and Figure 15 , respectively. These ultrasonic velocities increase continuously when carbonation occurs. Because the ultrasonic velocity in the air is smaller than in the dense material, the observations show an increase in the density, which is coherent with the results observed earlier. The characteristics of ultrasonic wave propagation in a material can provide valuable information on material properties, microstructure and damage state. These methods have many advantages: ease of implementation, ability to work with one side of the material, can pass through large thicknesses, obtaining immediate results of measurements. Furthermore, we can calculate the Poisson's ratio and dynamic modulus of elasticity from ultrasonic velocities as follow.

Poisson's ratio [20]:

$$
v=\frac{V_{\mathrm{L}}^{2}-2 V_{T}^{2}}{2 V_{L}^{2}-2 V_{T}^{2}}
$$

Dynamic modulus of elasticity [20]:

$$
E=2 \rho V_{\mathrm{T}}^{2}(1+v)
$$

with $\rho$ is the density of the material.

Figure 16 shows that the Poisson's ratio remains constant before and after carbonation. In contrast, the dynamic modulus of elasticity increases after carbonation (Figure 17). These observations show a positive influence of the carbonation on the cement based material, of course without taking into account the corrosion of rebar. This positive effect of the carbonation was already applied in the concrete industry, especially for the non reinforced concrete structures.

\subsubsection{Solid Phase Volume Determined by Helium Pycnometry}

Helium pycnometry was used to determine the solid phase volume of samples before and after carbonation. For 
comparison, the helium pycnometry analysis was also performed on samples which were subjected only to natural carbonation at $20^{\circ} \mathrm{C}$ and $65 \%$ relative humidity without additional $\mathrm{CO}_{2}$. The results are presented in Figure 18. We can see clearly that the accelerated carbonation resulted in a significant increase in the volume in comparison with the natural carbonated sample. The increase in the volume of the solid phase can be explained by the formation of $\mathrm{CaCO}_{3}$ during carbonation, because the carbonation of one mole of portlandite leads to an increase in volume of $4 \mathrm{~cm}^{3}$ [21], and the carbonation of one mole of C-S-H leads to an increase in volume of 12 $\mathrm{cm}^{3}$ [22] or $39 \mathrm{~cm}^{3} / \mathrm{mol}$ [2]. Due to differences in the volume, the carbonation product $\left(\mathrm{CaCO}_{3}\right)$ clogs the pores, thereby decreasing the porosity.

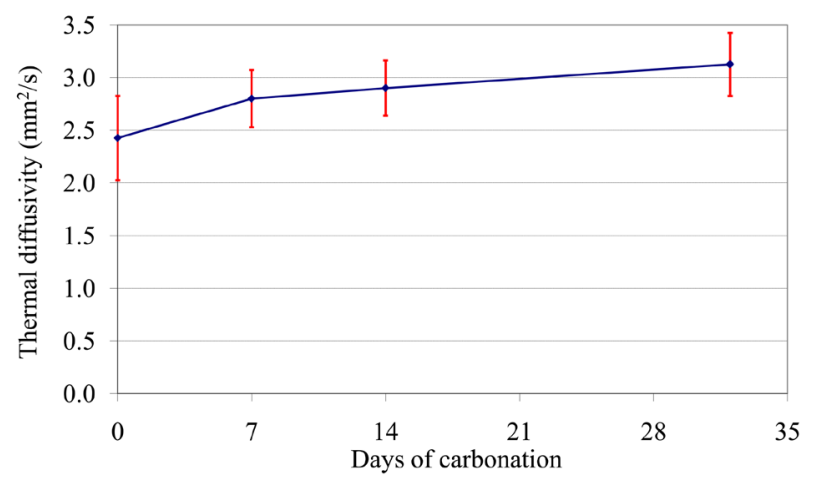

Figure 13. Evolution of the thermal diffusivity during carbonation.

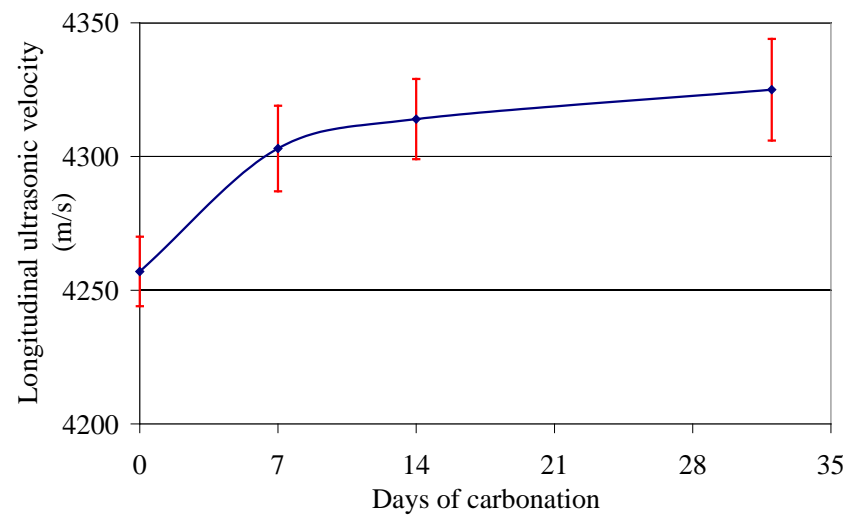

Figure 14. Evolution of the longitudinal ultrasonic velocity $\left(V_{L}\right)$ during carbonation.

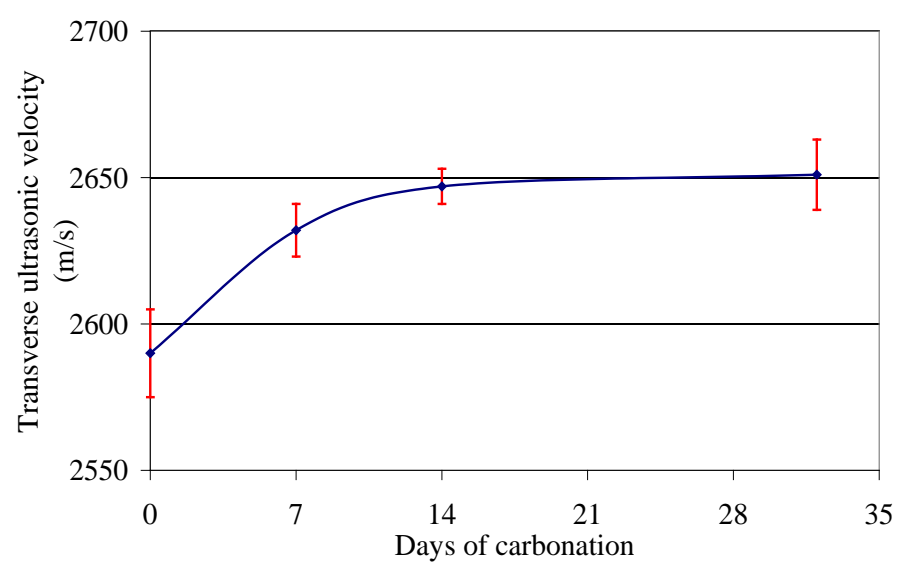

Figure 15. Evolution of the transverse ultrasonic velocity $\left(V_{T}\right)$ during carbonation. 


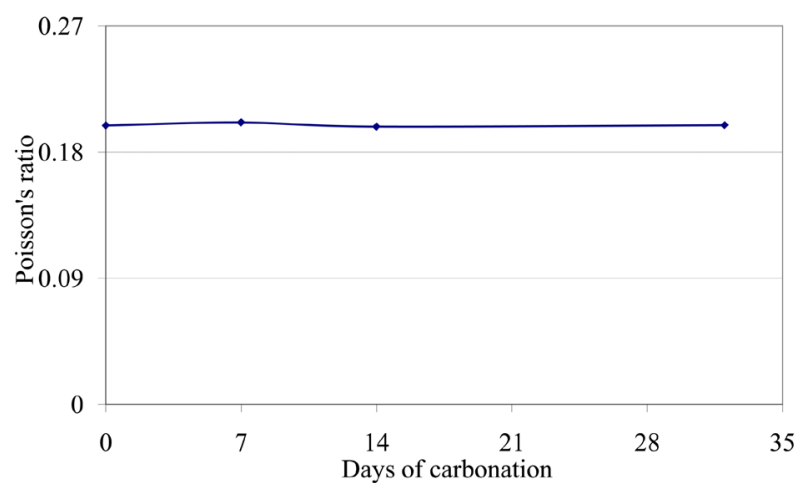

Figure 16. Evolution of the Poisson's ratio during carbonation.

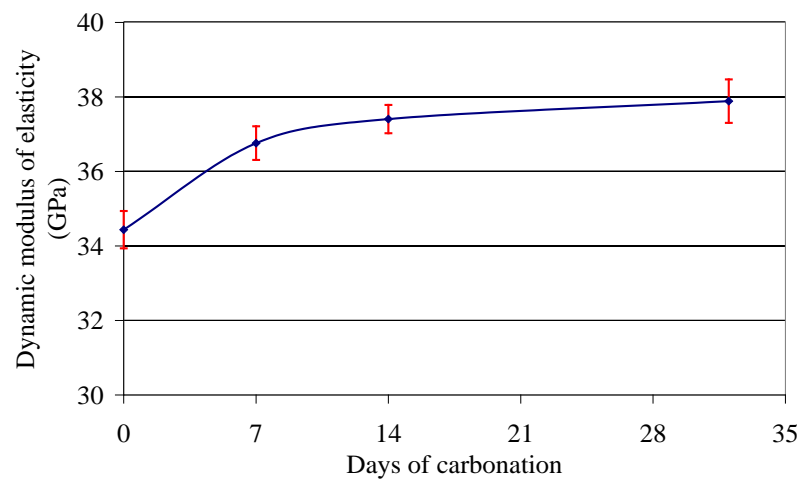

Figure 17. Evolution of the dynamic modulus of elasticity during carbonation.

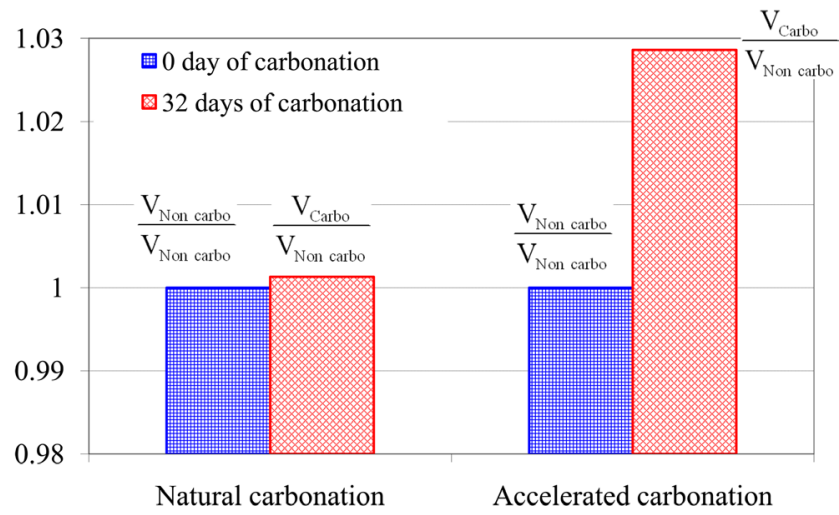

Figure 18. Evolution of the solid phase volume during accelerated carbonation and natural carbonation.

\section{Conclusions}

The results of this study indicate that microstructural changes due to carbonation depend not only on the characterization techniques but also on the type of materials. Regarding the type of technique, investigation using nitrogen adsorption gives information about micro and especially meso pores, while the one using porosity accessible to water covers all three domains: macro, meso, and especially micropores. This is because nitrogen and water molecules do not get access into the same porous domains due to difference in molecular sizes.

Thus, the porosity determined by nitrogen adsorption increase when carbonation occurs. In contrast, the porosity accessible to water decreases after carbonation. In others words, the quantity of adsorbed nitrogen increases while the quantity of retained water decreases after carbonation. 
The combination of the two techniques allows drawing a conclusion that, after carbonation, the volume of mesopores increases at the expense of the volume of micropores. However, the increase in mesopores volume is only significant for pores with radius around $2 \mathrm{~nm}$, while this increase in volume is nearly negligible for pores with radius larger than $2 \mathrm{~nm}$. This result indicates that, after carbonation, cementitious materials based on composed cement is much more sensible to the creation of mesopores than CEM I cement mortars.

The evolution of the specific surface area is correlated with the evolution of the mesopores volume. Indeed, the insignificant increase in the mesopores volume leaded to an insignificant variation of the specific surface.

The decrease in the volume of micropores and in the total volume is explained by the formation of $\mathrm{CaCO}_{3}$ during carbonation which obstructs the pores. This results in the increase of the solid phase volume is determined by helium pycnometry. Another consequence is the increase of thermal properties and ultrasonic velocities after carbonation, as well as the dynamic modulus of elasticity. These observations indicate a positive consequence of carbonation on cement-based materials in term of strength at the expense of the thermal and sonic insulation.

It appears that the gas intrinsic permeability is largely influenced by the mesopores volume. The results show that the increase in volume of mesopores after carbonation might be the cause of the increase in the intrinsic permeability to helium. Furthermore, the gas permeability increases slightly, which is correlated with the slight increase of the volume of mesopores.

\section{References}

[1] (2004) Véronique Baroghel Bouny, Conception des bétons pour une durée de vie donnée des ouvrages. Association française de génie civil.

[2] Mickaël, T. (2005) Modelling of Atmospheric Carbonation of Cement Based Materials Considering the Kinetic Effects and Modifications of the Microstructure. Ph.D. Thesis, L'école nationale des ponts et chausses, Paris.

[3] Ngala, V.T. and Page, C.L. (1997) Effects of Carbonation on Pore Structure and Diffusional Propeties of Hydrated Cement Pastes. Cement and Concrete Research, 27, 995-1007. http://dx.doi.org/10.1016/S0008-8846(97)00102-6

[4] Jaafar, W. (2003) Influence de la carbonatation sur la porosité et la perméabilité des bétons, Diplôme d'études approfondies. Master of Advanced Studies, Laboratoire Central des Ponts et Chaussées, Paris.

[5] Hiromitu, N. and Masako, H. (1991) Analysis of Adsorption Isotherms of Water Vapour for Nonporous and Porous Adsorbents. Journal of Colloid and Interface Science, 145, 405-412. http://dx.doi.org/10.1016/0021-9797(91)90371-E

[6] De Belie, N., Kratky, J. and Van Vlierberghe, S. (2010) Influence of Pozzolans and Slag on the Microstructure of Partially Carbonated Cement Paste by Means of Water Vapour and Nitrogen Sorption Experiments and BET Calculations. Cement and Concrete Research, 40, 1723-1733. http://dx.doi.org/10.1016/j.cemconres.2010.08.014

[7] Zhang, Q., Ye, G. and Koenders, E. (2013) Investigation of the Structure of Heated Portland Cement Paste by Using Various Techniques. Construction and Building Materials, 38, 1040-1050. http://dx.doi.org/10.1016/j.conbuildmat.2012.09.071

[8] Brunauer, S., Emmett, P.H. and Teller, E. (1938) Adsorption of Gases in Multimolecular Layers, Journal of American Chemical Society, 60, 309-319. http://dx.doi.org/10.1021/ja01269a023

[9] Bier, Th.A., Kropp, J. and Hilsdorf, H.K. (1987) Carbonation and Realkalinization of Concrete and Hydrated Cement Paste. In: Maso, J.C., Ed., Durability of Construction Materials, Vol. 3, RILEM, Chapman \& Hall Publishers, London, New York, 927-934.

[10] Association française pour la construction et pour la recherche et les essais sur les matériaux et les constructions (A.F.P.C.-A.F.R.E.M) (1997) Essai de carbonatation accéléré, mesure de l’épaisseur de béton carbonate. In: Ollivier, J.P., Ed., Durabilité des bétons-Méthodes recommandées pour la mesure des grandeurs associées à la durabilité, Laboratoire des Matériaux et Durabilité des Constructions, Toulouse, 153-158.

[11] Barrett, E.P., Joyner, L.G. and Halenda, P.P. (1951) The Determination of Pore Volume and Area Distributions in Porous Substances. I. Computations from Nitrogen Isotherms. Journal of the American Chemical Society, 73, 373-380. http://dx.doi.org/10.1021/ja01145a126

[12] Kollek, J.J. (1989) The Determination of the Permeability of Concrete to Oxygen by the CEMBUREAU Method-A Recommendation. Materials and Structures, 22, 225-230. http://dx.doi.org/10.1007/BF02472192

[13] Carde, C. (2006) La Carbonatation. Le magazine Béton, 2, 53-54.

[14] Eitel, W. (1966) Silicate Science: Ceramics and Hydraulic Binders. Vol. 5, Academic Press, New York.

[15] Swenson, E.G. and Sereda, P.J. (1968) Mechanism of the Carbonation Shrinkage of Lime and Hydrated Cement. Journal of Applied Chemistry, 18, 111-117. 
[16] Houst, F.Y. and Wittmann, F.H. (1989) Retrait de Carbonatation. IABSE Symposium, Lisbon, 14-17 September 2005, 255-260.

[17] Association française pour la construction et pour la recherche et les essais sur les matériaux et les constructions (A.F.P.C.-A.F.R.E.M) (1997) Détermination de la masse volumique apparente et de la porosité accessible à l'eau. In: Ollivier, J.P., Ed., Durabilité des béton-Méthodes recommandées pour la mesure des grandeurs associées à la durabilité, Laboratoires des Matériaux et Durabilité des Constructions, Toulouse, 121-124.

[18] RILEM TC 116-PCD (1999) Permeability of Concrete as a Criterion of Its Durability. Materials and Structure, 32, 163 -173 .

[19] Neville, A.M. (1990) Properties of Concrete. Longman Scientific and Technical, London.

[20] Luo, Q.X. and Bungey, J.H. (1996) Using Compression Wave Ultrasonic Transducers to Measure the Velocity of Surface Waves and Hence Determine Dynamic Modulus of Elasticity for Concrete. Construction and Building Materials, 4, 237-242. http://dx.doi.org/10.1016/0950-0618(96)00003-7

[21] Papadakis, V.G., Vayenas, C.G. and Fardis, M.N. (1989) A Reaction Engineering Approach to the Problem of Concrete Carbonation. AIChE Journal, 35, 1639-1650. http://dx.doi.org/10.1002/aic.690351008

[22] Papadakis, V.G., Vayenas, C.G. and Fardis, M.N. (1991) Fundamental Modelling and Experimental Investigation of Concrete Carbonatation. ACI Material Journal, 88, 363-373. 
Scientific Research Publishing (SCIRP) is one of the largest Open Access journal publishers. It is currently publishing more than 200 open access, online, peer-reviewed journals covering a wide range of academic disciplines. SCIRP serves the worldwide academic communities and contributes to the progress and application of science with its publication.

Other selected journals from SCIRP are listed as below. Submit your manuscript to us via either submit@scirp.org or Online Submission Portal.
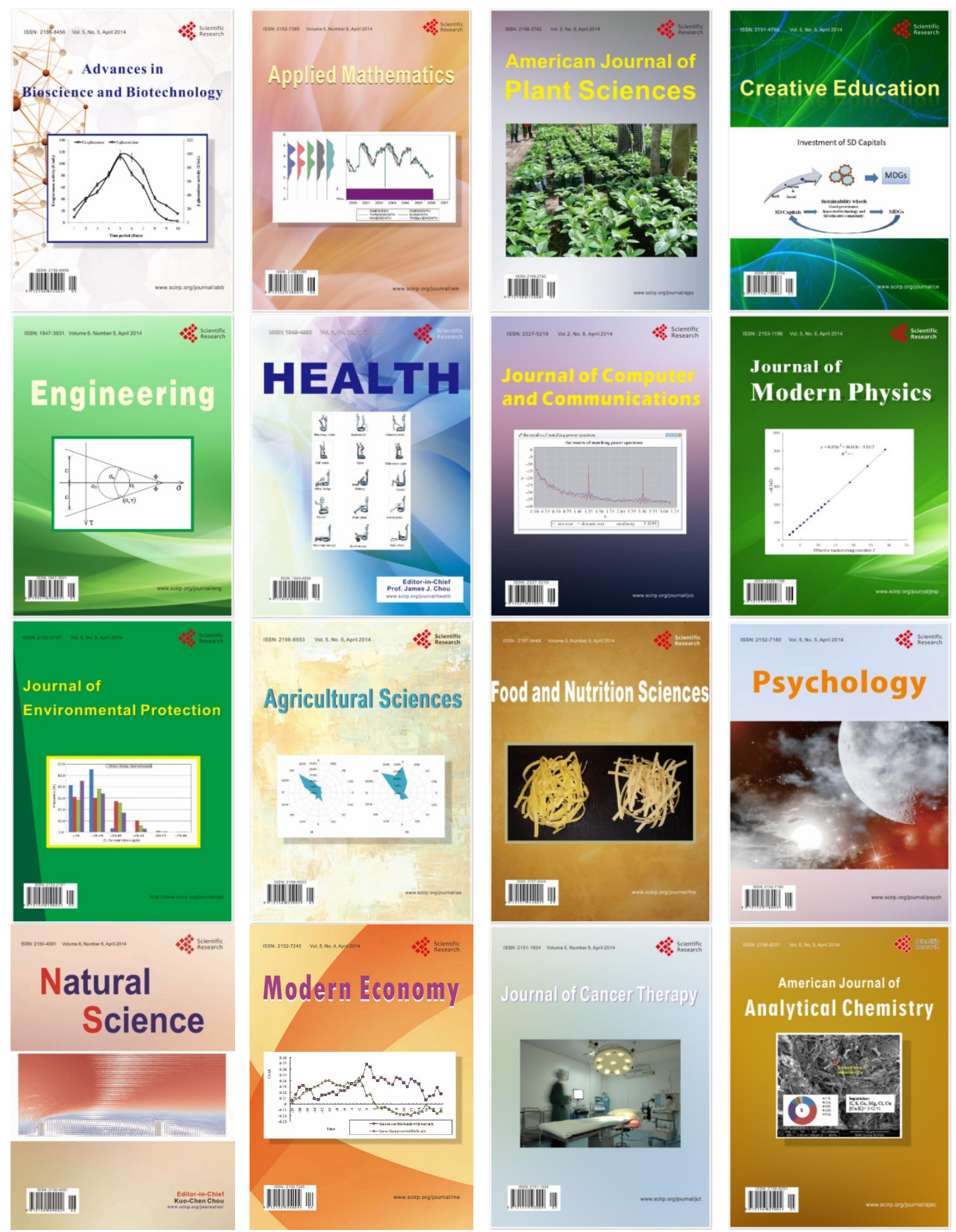